\title{
The Association Between Ventilatory Ratio and Mortality of Adult Patients with ARDS: Systematic Review and Meta-Analysis
}

\section{Lianlian Jiang}

Southeast University

\section{Wei Chang}

Southeast University

\section{Xueyan Yuan}

Southeast University

Qin Sun

Southeast University

\section{Zihan $\mathrm{Hu}$}

Southeast University

\section{Jianfeng Xie}

Southeast University

Yi Yang ( $\nabla$ yiyiyang2004@163.com )

Nanjing Zhongda Hospital, Southeast University https://orcid.org/0000-0003-1661-3568

\section{Research Article}

Keywords: Ventilatory ratio, Acute respiratory distress syndrome, VR囚ARDS, Mortality, Prognosis

Posted Date: December 6th, 2021

DOI: https://doi.org/10.21203/rs.3.rs-1100551/v1

License: (c) (i) This work is licensed under a Creative Commons Attribution 4.0 International License. Read Full License 
The association between ventilatory ratio and mortality of adult patients with ARDS: systematic review and meta-analysis

Lianlian Jiang ${ }^{1}$, Wei Chang ${ }^{1}$, Xueyan Yuan ${ }^{2}$, Qin $\mathrm{Sun}^{3}$, Zihan $\mathrm{Hu}^{4}$, Jianfeng $\mathrm{Xie}^{1 *}, \mathrm{Yi}$ Yang $^{1 *}$

Author affiliations: ${ }^{1234}$ Jiangsu Provincial Key Laboratory of Critical Care Medicine, Department of Critical Care Medicine, Zhongda Hospital, School of Medicine, Southeast University, Nanjing 210009, Jiangsu, China

Correspondence to: ${ }^{1 *}$ Yi Yang, Jiangsu Provincial Key Laboratory of Critical Care Medicine, Department of Critical Care Medicine, Zhongda Hospital, School of Medicine, Southeast University, Nanjing 210009, China. Fax: 00862583262500, Telephone: 00862583262500, E-mail: yiyiyang2004@163.com. 


\section{Authors list:}

1. Lianlian Jiang, Jiangsu Provincial Key Laboratory of Critical Care Medicine, Department of Critical Care Medicine, Zhongda Hospital, School of Medicine, Southeast University, Nanjing 210009, Jiangsu, China ; lianlianjiang2020@163.com

2. Wei Chang, Jiangsu Provincial Key Laboratory of Critical Care Medicine, Department of Critical Care Medicine, Zhongda Hospital, School of Medicine, Southeast University, Nanjing 210009, Jiangsu, China; ewei_0181@126.com

3. Xueyan Yuan, Jiangsu Provincial Key Laboratory of Critical Care Medicine, Department of Critical Care Medicine, Zhongda Hospital, School of Medicine, Southeast University, Nanjing 210009, Jiangsu, China；18826401594@163.com

4. Qin Sun, Jiangsu Provincial Key Laboratory of Critical Care Medicine, Department of Critical Care Medicine, Zhongda Hospital, School of Medicine, Southeast University, Nanjing 210009, Jiangsu, China; sunqin1990seu@126.com

5. Zihan $\mathrm{Hu}$, Jiangsu Provincial Key Laboratory of Critical Care Medicine, Department of Critical Care Medicine, Zhongda Hospital, School of Medicine, Southeast University, Nanjing 210009, Jiangsu, China; allnormal@126.com

6. Jianfeng Xie, Jiangsu Provincial Key Laboratory of Critical Care Medicine, Department of Critical Care Medicine, Zhongda Hospital, School of Medicine, Southeast University, Nanjing 210009, Jiangsu, China; xie820405@126.com

7. Yi Yang, Jiangsu Provincial Key Laboratory of Critical Care Medicine, Department of Critical Care Medicine, Zhongda Hospital, School of Medicine, Southeast University, Nanjing 210009, Jiangsu, China; yiyiyang2004@163.com 


\section{Abstract}

Background: Ventilatory ratio is a simple bedside index of impaired efficiency of ventilation and correlates well with physiological dead space fraction in patients with ARDS. So it was regarded as a dead-space marker associated with mortality in mechanically ventilated adults with ARDS. However, the association between VR and outcome of patients with ARDS remains largely unknown.

Methods: We searched articles in three electronic databases including PubMed, EMBASE and Web of Science. All the English publications until $1^{\text {st }}$ Oct. 2021 will be searched without any restriction of countries. All the observational study that investigated the association between ventilatory ratio and the mortality of ARDS patients were identified in this meta-analysis. The main outcome was mortality. Summary estimates of effect using odds ratio (OR) for dichotomous outcomes with accompanying $95 \%$ confidence interval (CI) were expressed.

Results: A total of 9 trials enrolling 5638 patients were finally included in this meta-analysis. The results revealed that the use of ventilatory ratio could be significantly related to the mortality in adult ARDS (OR=1.27; 95\% CI 1.10 to 1.47; $\mathrm{P}=0.001)$. Ventilatory ratio may have the capability of predicting the mortality of NON- COVID-related patients (OR $1.39,95 \% \mathrm{CI} 1.12$ to $1.73 \mathrm{P}=0.003)$ while it has no predictable significance in patients with COVID (OR 1.18, 95\% CI 0.94 to $1.48 \mathrm{P}$ $=0.16)$. Importantly, the dynamic changes of VR adds more predictable value (OR 1.21 vs 1.19$)$.

Conclusion: Our study suggests that ventilatory ratio can be regarded as a valuable marker to predict the mortality of adult patients with ARDS. Compared to patients with COVID, ventilatory ratio is more predictable in patients with NON-COVID. What's more, the dynamic changes of VR may have the potential to improve the prognostic value.

Keywords: Ventilatory ratio, Acute respiratory distress syndrome, VR, ARDS, Mortality, Prognosis 


\section{Background}

Quantifying acute respiratory disease syndrome (ARDS) severity is essential for prognostic enrichment to stratify patients for precise treatments. The new definition of ARDS still retains the $\mathrm{PaO}_{2} / \mathrm{FIO}_{2}$ ratio as the only measured variable [1] despite evidence suggesting it as a poor predictor of outcome [2]. Conversely, dead space measurement has been shown to be useful in monitoring disease progression of ARDS and is a predictor of mortality in patients with ARDS [3].

Dead space measurement is a crucial part to estimate the adequacy of ventilation among mechanically ventilated patients with ARDS. Physiological dead space fraction (dead space to tidal volume ratio, VD/VT) and $\mathrm{CO}_{2}$ production indicate the ventilatory demands of the body [4]. Several studies have demonstrated the value of VD/VT in critically ill patients in both prognostication and disease progression of ARDS [3]. Yet due to the complexity or equipment costs associated with its calculation, VD/VT is seldom measured in daily intensive care unit (ICU) practice. Therefore, a similar quick measurement is in need.

Recently, a new index, ventilatory ratio (VR), defined as [minute ventilation ( $\mathrm{mL} / \mathrm{min}$ ) $\left.\times \mathrm{PaCO}_{2}(\mathrm{mmHg})\right] /$ [predicted body weight $\left.\times 100(\mathrm{~mL} / \mathrm{min}) \times 37.5(\mathrm{mmHg})\right]$, has been described to monitor impaired efficiency of ventilation using commonly collected bedside variables and correlates well with VD/VT in patients with ARDS [5]. High value of ventilatory ratio was found to be associated with poorer outcomes in patient with ARDS [6-7]. However, Bhalla has proposed the opposite idea that VR should not be used for prognostic purposes in young adults [8]. In patients with Corona Virus Disease-19 (COVID-19), the findings were even inconsistent. While Fusina supported it as a bedside factor to predict the mortality [5], both Ende and Morales-Quinteros found that it may not yield prognostic information when added to a baseline risk model though ventilatory impairment seems to be obvious in non-survivors of COVID-19[9-10]. The association between VR and the mortality of mechanically ventilated patients with ARDS remains largely unknown. 
Therefore, we conducted a comprehensive systematic review and meta-analysis to evaluate the association between ventilatory ratio and the mortality of adult patients with ARDS in observational studies.

\section{Methods}

This systematic review and meta-analysis was performed according to the Meta-analysis Of Observational Studies in Epidemiology (MOOSE) statement and Preferred Reporting Items for Systematic Reviews and Meta-Analyses (PRISMA) statement [11-12] (Additional File 1) and was registered at PROSPERO with the registration number CRD42021282517.

\section{Information sources}

Two researchers independently searched relevant English articles in three electronic databases including PubMed, EMBASE and Web of Science up to October 1, 2021. We restricted the articles to those published in English. A backward snowballing was performed to obtain potentially eligible studies based on the reference list of all selected articles. If necessary, we would try to contact the authors for further information.

\section{Search strategy}

The following key words were used in the search: "ventilatory ratio," "acute respiratory distress syndrome," "adult respiratory distress syndrome," "ARDS, Human," and "shock lung." The full search strategy is included in Additional File 2. We searched articles in three electronic databases including PubMed, EMBASE and Web of Science. Relevant articles will be independently searched by two investigators and disagreement was resolved in consultation with a third author.

\section{Eligibility criteria}

We included all observational studies. Studies that met the following criteria were included in this meta-analysis: (i) study population of mechanically ventilated adults with ARDS without limitation on its diagnostic criteria, (ii) patients are no less than 18 years old, (iii) observational study design that investigated the association between 
ventilatory ratio and mortality, and (iiii) the odds ratios (OR) and the corresponding 95\% confidence intervals (CIs) or the number of events that can calculate them were reported. The exclusion criteria were as follows: (i) duplicates or overlapping populations, (ii) in vitro or animal experiments, (iii) non-original articles (e.g. case reports or case series, letter to editors, abstracts, editorials and poster presentations).

The primary outcome was mortality, and the secondary outcomes were clinical outcomes, including ICU-free days (IFDs), and ventilator-free days (VFDs).

\section{Selection of studies}

We merged the search results and removed the duplicate records of the same study. Titles and abstracts were then reviewed independently by two researchers for potential eligibility. When potentially relevant studies were found, full-text manuscripts were also retrieved for further inspection separately. Two authors will independently extract data. Any disagreement will be resolved by consulting a third author. The following data will be extracted: author, year of publication, setting, study design, diagnostic criteria, clinical type, number of patients included in the study, number of cases and controls if possible, male\%, age, ventilatory ratio, $\mathrm{PaO}_{2}$ to $\mathrm{FiO}_{2}$ ratio $\left(\mathrm{PaO}_{2} / \mathrm{FiO}_{2}\right)$, positive end expiratory pressure (PEEP), driving pressure (DP), pulmonary dead space fraction (VD/VT) , mortality, OR and 95\%CI, ICU-free days, and ventilator-free days.

\section{Quality assessment}

Two reviewers will independently assessed the Internal validity and risk of bias of the selected case-control and cohort studies according to the Newcastle-Ottawa Scale (NOS). NOS consists of three parameters of quality which assigns a maximum star of 4 for selection, 2 for comparability, and 3 for exposure. Stars $\geq 6$ was regarded as high quality. Discrepancies were resolved in consultation with a third author. 


\section{Statistical analysis}

The data extracted from the articles were analyzed by Review Manager 5.4.1 (The Nordic Cochrane Centre, The Cochrane Collaboration, 2020). A two-tailed P value less than 0.05 was considered statistically significant.

For dichotomous variables, the estimated effects were pooled with Mantel-Haenszel method and expressed with the odds ratio (OR) with $95 \%$ confidence interval (CI). For the continuous variables, the estimated effects were pooled with the inverse variance model and expressed with the mean difference (MD) with 95\% CI.

Heterogeneity was evaluated using the Cochran's Q test, a Chi-square test, with a threshold $\mathrm{P}$ value of less than 0.10 . The impact of heterogeneity on outcomes was assessed using $\mathrm{I}^{2}$ statistic. $\mathrm{I}^{2}$ greater than or equal to $50 \%$ was considered as statistically significant heterogeneity. The choice between fixed-effect or random-effect models was based on statistical heterogeneity. If $\mathrm{P}<0.10$ with the Chi square test or $\mathrm{I}^{2}>50 \%$, a random-effects model was used to pool data; otherwise, the fixed-effect model was used.

For sensitivity analysis, we removed each study sequentially and then reanalyzed the remaining dataset to evaluate the robustness of the results. Funnel plots and Egger's test was used to assess the presence of publication bias on the primary outcome by visual inspection.

Subgroup analysis was conducted to analyze the origin of heterogeneity of ventilatory ratio based on sub-population of patients with different clinical types (COVID vs NON-COVID), different diagnostic criteria and different definitions of mortality.

\section{Results}

\section{Results of the search}

We identified 59 records in accordance with the search strategy and retrieved the full text of 34 studies for possible eligibility. The flowchart of our search process is presented in Fig. 1. Of the 34 studies, 9 studies met all inclusion criteria and were 
included in the final quantitative synthesis[2、5-7、9-10、13-15]. The nine included studies comprised a total of 5638 patients.

\section{Study selection and characteristics}

Study characteristics and patient characteristics are summarized in Table 1 and the details of dynamic changes of ventilatory ratio was recorded in Table 2. All the included studies were published between 2013 and 2021. All the nine studies were observational studies.

\section{Primary outcome}

A total of 9 studies, involving 5638 patients, were included in the analysis for the primary outcome. The meta-analysis using a random-effect model showed a statistically significant risk of mortality for patients with high ventilatory ratio $(\mathrm{OR}=1.27 ; 95 \% \mathrm{CI} 1.10$ to $1.47 ; \mathrm{P}=0.001)$ (Fig. 2). Importantly, D2-VR is more relevant than D1-VR $(\mathrm{OR}=1.21 ; 95 \% \mathrm{CI} 1.08$ to $1.35 ; \mathrm{P}=0.0009$ vs $\mathrm{OR}=1.19 ; 95 \% \mathrm{CI}$ 1.07 to $1.33 ; \mathrm{P}=0.002$ ) (Fig. 3).

\section{Risk of bias and sensitivity analysis}

Assessment of the risk of bias in included studies is shown in Additional File 3. Since most of the analyses were exploratory with existing database or recorded data, the overall quality of these studies was high. when each trial was sequentially omitted from the meta-analysis to evaluate the individual effects of the trial on the overall results, the results did not show any significant differences (Additional File 4). Visual inspection of a funnel plot on mortality was evaluated and suggest the evidence of potential publication bias (Additional File 5).

\section{Subgroup analysis}

According to the origin of ARDS, we first divided patients of the included studies into two categories, namely COVID and NON-COVID. Four studies included patients who were classified into type of COVID. The result showed that ventilatory ratio has increasingly significance of predicting the mortality of NON-COVID-related patients (OR $1.39,95 \%$ CI 1.12 to $1.73 \mathrm{P}=0.003)$, while it has no predictable significance in 
patients with COVID-related patients (OR 1.18, 95\% CI 0.94 to $1.48 \mathrm{P}=0.16$ ) (Fig. 4). Also, the subgroup analysis based on the definition of mortality showed that when hospital mortality was used as the clinical outcome, the result has more possibility to be significantly different (OR $1.55,95 \%$ CI 1.11 to $2.16 \mathrm{P}=0.01)$ (Fig. 5). It is worth mentioning that articles published by Sinha account too much on the significant results (OR $1.6295 \%$ CI 1.17 to $2.25 \mathrm{P}=0.004$ ) (Fig. 6). We have also made subgroup analysis according to the diagnostic criteria which turned out to make some sense in patients diagnosed without Berlin criteria (OR 1.38, 95\% CI 1.09 to $1.74 \mathrm{P}=$ 0.007) (Additional File 6).

\section{Discussion}

This is the first meta-analysis, to our knowledge, to demonstrate the association between ventilatory ratio and the mortality of ventilated patients with ARDS. Our meta-analysis assessed its association in 9 studies with 5638 cases. We confirmed, consistent with most of the previous researches, that ventilatory ratio adds prognostic value to the mortality and severity of mechanically ventilated patients with ARDS. Importantly, D2-VR is more predictable than D1-VR which may push us to focus more on the dynamic changes of ventilatory ratio. However, attention paid to other clinical outcomes caused by ventilatory ratio was rare which has resulted in the lack of the analysis of our secondary outcomes.

There was a significant overall heterogeneity $\left(\mathrm{I}^{2}=69 \%\right)$. Since all the researches were exploratory, we had to make the analysis with the adjusted odds ratio by multivariable analysis and failed to make a meta regression because of the lack of control group. So we tried to make full use of the extracted data to make subgroup analysis. As can be seen from the results, subsequent subgroup analysis divided by origin of ARDS might partially explain it since only the type of patients with NON-COVID was found to be significantly different. What's more, the subgroup analysis according to the definition of mortality, diagnostic criteria, and researcher of the articles with the random effects 
model can also solve the problem of heterogeneity in some ways. However, the difference of the adjusted factors was believed to contribute most, whose details can be viewed in additional file 2 .

The ventilatory ratio is a recently validated index that is appealing because it is easily-acquired and can be considered as a surrogate marker of physiologic dead space [15]. Interpretation of the ventilatory ratio is complex because it can be affected by both dead space and $\mathrm{CO}_{2}$ production [13]. In ARDS, changes in dead space are likely to be of a greater relative magnitude than $\mathrm{CO}_{2}$ production. Nevertheless, changes in the latter may also adversely influence VR's prognostic value [16].

The mortality of COVID-19-related ARDS is extremely high, especially in those patients that require invasive mechanical ventilation (MV)[17]. Barbeta have previously reported that the ventilatory ratio is elevated in COVID-related ARDS patients [18]. Schenck et al.[19]also found higher values in 267 COVID-related ARDS patients that remained intubated at day 3 and 7. According to recent researches, most of them believed that Patients with COVID-associated ARDS have a similar form of injury to that of those with ARDS unrelated to COVID-19[20-21]. Conversely, we found ventilatory ratio did not add prognostic value of mortality in the subgroup of patients with COVID compared to NON-COVID.

The following reasons may be considered as explanations. First, ventilatory ratio can increase as a consequence of the progression of disease which means its predictable value may be improved over time. Since our analysis just take use of its baseline data, it can produce false negative. Second, the differences between COVID-19-related ARDS and classical ARDS could be influenced by its pathophysiological differences since the former had a viral origin whereas the latter can have various causes [22]. It is recognized that patients with COVID suffered from an elevated dead space due to a combination of hypoperfused alveoli caused by microthrombosis and pulmonary microvascular endothelial damage [23-24]. Therefore, the dead space may be a weaker predictor to reflect oxygenation when patients were accompanied with mild 
hypercapnia. Third, there are many other factors not captured by our analysis such as comorbidities and interventions during ICU stay which can affect the results. As such, it might have important implications for the clinical management of patients with COVID-19-related ARDS.

The observational nature of included study is its major weakness and resulted in the uncontrolled heterogeneity of the study. First, all the studies are prospective observational designs and conducted with no interference in the routine clinical practice resulting its invalidity of quality assessment. What's more, most of them belong to post hoc analysis with different definition of mortality. Second, the authors' efforts to contact the author of the original articles to get more information were not as successful as hoped, so this meta-analysis information depends on only already-published data which is the reason why we choose to use simple effect size analysis, resulting in the heterogeneity with high possibility. Finally, there is possibly a publication bias against smaller and non-positive studies as suggested by the above visual inspection of the funnel plot. For generalization of these meta-analysis results, larger number of prospective consecutive studies to investigate the prognostic value of VR with receiver operating characteristic curve (ROC) might be warranted. In this study, despite its limitations, there is a strong signal that associates VR with mortality in ARDS. Splitting the ARDS population using VR into those patients with failure of oxygenation (type I) and those with a failure of $\mathrm{CO} 2$ elimination (type II) makes intuitive sense and is associated with clinically meaningful subgroups [16]. Such categories may also facilitate a better understanding of pathophysiological processes of ARDS and lead to more consistent management strategies [25]. 


\section{Conclusion}

Given that ventilatory ratio is easy to calculate and yields information about ventilatory adequacy, it is significantly associated with the mortality of mechanically ventilated patients with ARDS. Importantly, compared to patients with COVID, ventilatory ratio is more predictable in patients with NON-COVID. Large number of further studies are needed to make full use of the dynamic changes of ventilatory ratio.

\section{Abbreviations}

ARDS: Acute respiratory distress syndrome; VR: Ventilatory ratio; OR: Odds ratio; MD: Mean difference; CI: Confidence interval; AECC: American-European Consensus Conference; COVID: Corona Virus Disease-19; NON-COVID: Not Corona Virus Disease-19; P/F: Ratio of arterial oxygen partial pressure to fractional inspired oxygen;

VD/VT: Dead space to tidal volume ratio; ICU: Intensive care unit; IFDs: ICU-free days; VFDs: Ventilator-free days; PEEP: Positive end expiratory pressure; DP: Driving pressure; ROC: Receiver operating characteristic curve. 


\section{Declarations}

\section{Acknowledgements}

Not applicable.

\section{Conflict of interest}

The authors declare that they have no competing interests.

\section{Authors' contributions}

LJ and WC searched the scientific literature, collected the data, performed statistical analyses and drafted the manuscript. XY and QS contributed to the conception, design, and data interpretation. JX and YY contributed to the conception, design, data interpretation, manuscript revision for critical intellectual content, and supervision of the study. $\mathrm{ZH}$ participated in data interpretation and revising the manuscript.

\section{Consent for publication}

All authors have confirmed the manuscript and approved the publication of the manuscript.

\section{Ethics approval and consent to participate}

Not applicable.

\section{Availability of data and materials}

All data generated or analysed during this study are included in this published article and its supplementary information files.

\section{Funding}

This work was supported by National Natural Science Foundation of China (grant numbers 81971888 and 82072155$)$. 


\section{Reference}

1 Force ADT, Ranieri VM, Rubenfeld GD, et al. Acute respiratory distress syndrome: the Berlin Definition. JAMA. 2012;307(23):2526-33.

2 Torres A, Motos A, Riera J, et al. CIBERESUCICOVID Project (COV20/00110, ISCIII). The evolution of the ventilatory ratio is a prognostic factor in mechanically ventilated COVID-19 ARDS patients. Crit Care. 2021;25(1):331.

3 Nuckton TJ, Alonso JA, Kallet RH, et al. Pulmonary dead-space fraction as a risk factor for death in the acute respiratory distress syndrome. N Engl J Med. 2002; 346: $1281-6$.

4 Sinha P, Fauvel NJ, Singh S, Soni N. Ventilatory ratio: a simple bedside measure of ventilation. Br J Anaesth. 2009;102(5):692-4.

5 Fusina F, Albani F, Bertelli M, et al. Corrected Minute Ventilation Is Associated With Mortality in ARDS Caused by COVID-19. Respir Care. 2021;66(4):619-625.

6 Sinha P, Calfee CS, Beitler JR, et al. Physiologic Analysis and Clinical Performance of the Ventilatory Ratio in Acute Respiratory Distress Syndrome. Am J Respir Crit Care Med. 2019;199(3):333-341.

7 Sinha P, Singh S, Hardman JG, et al. Australia and New Zealand Intensive Care Society Clinical Trials Group. Evaluation of the physiological properties of ventilatory ratio in a computational cardiopulmonary model and its clinical application in an acute respiratory distress syndrome population. $\mathrm{Br} \mathrm{J}$ Anaesth. 2014;112(1):96-101.

8 Bhalla AK, Dong J, Klein MJ, et al. The Association Between Ventilatory Ratio and Mortality in Children and Young Adults. Respir Care. 2021;66(2):205-212.

9 Ende VJ, Singh G, Babatsikos I, et al. Survival of COVID-19 Patients With Respiratory Failure is Related to Temporal Changes in Gas Exchange and Mechanical Ventilation. J Intensive Care Med. 2021;36(10):1209-1216. 
10 Morales-Quinteros L, Neto AS, Artigas A, et al. PRoVENT-COVID Study Group. Dead space estimates may not be independently associated with 28-day mortality in COVID-19 ARDS. Crit Care. 2021;25(1):171.

11 Stroup DF, Berlin JA, Morton SC, et al. Meta-analysis of observational studies in epidemiology: a proposal for reporting. Meta-analysis Of Observational Studies in Epidemiology (MOOSE) group. JAMA. 2000;283(15):2008-12.

12 Liberati A, Altman DG, Tetzlaff J, et al. The PRISMA statement for reporting systematic reviews and meta-analyses of studies that evaluate healthcare interventions: explanation and elaboration. BMJ. 2009;339:b2700.

13 Morales-Quinteros L, Schultz MJ, Bringué J, et al. MARS Consortium. Estimated dead space fraction and the ventilatory ratio are associated with mortality in early ARDS. Ann Intensive Care. 2019;9(1):128.

14 Sinha P, Sanders RD, Soni N, et al. Acute respiratory distress syndrome : the prognostic value of ventilatory ratio--a simple bedside tool to monitor ventilatory efficiency. Am J Respir Crit Care Med. 2013;187(10):1150-3.

15 Sinha P, Fauvel NJ, Singh P, Soni N. Analysis of ventilatory ratio as a novel method to monitor ventilatory adequacy at the bedside. Crit Care. 2013;17(1):R34.

16 Liu X, Liu X, Xu Y, et al. Ventilatory Ratio in hyper- capnic mechanically ventilated patients with COVID-19 associated ARDS. Am J Respir Crit Care Med. 2020.

17 Lim ZJ, Subramaniam A, PonnapaReddy M, et al. Case Fatality Rates for Patients with COVID-19 Requiring Invasive Mechanical Ventilation. A Meta-analysis. Am J Respir Crit Care Med. 2021;203(1):54-66.

18 Barbeta E, Motos A, Torres A, et al. SARS-CoV-2-induced acute respiratory distress syndrome: pulmonary mechanics and gas-exchange abnormalities. Ann Am Thorac Soc. 2020;17(9):1164-8. 
19 Schenck EJ, Hoffman K, Goyal P, et al. Respiratory mechanics and gas exchange in COVID-19-associated respiratory failure. Ann Am Thorac Soc. 2020;17(9):1158-61.

20 Grasselli G, Tonetti T, Protti A, et al. Pathophysiology of COVID-19-associated acute respiratory distress syndrome: a multicentre prospective observational study. Lancet Respir Med. 2020;8(12):1201-1208.

21 Grieco DL, Bongiovanni F, Chen L, et al. Respiratory physiology of COVID-19-induced respiratory failure compared to ARDS of other etiologies. Crit Care. 2020;24(1):529.

22 Gattinoni L, Coppola S, Cressoni M, et al. Covid-19 does not lead to a typical Acute Respiratory Distress Syndrome. Am J Respir Crit Care Med. 2020.

23 Diehl JL, Peron N, Chocron R,et al. Respiratory mechanics and gas exchanges in the early course of COVID-19 ARDS: a hypothesis-generating study. Ann Intensive Care. 2020;10(1):95.

24 Patel BV, Arachchillage DJ, Ridge CA, Bianchi P, Doyle JF, Garfield B, et al. Pulmonary angiopathy in severe COVID-19: physiologic, imaging, and hematologic observations. Am J Respir Crit Care Med. 2020;202(5):690-9.

25 Beloncle F, Studer A, Seegers V, et al. Longitudinal changes in compliance, oxygenation and ventilatory ratio in COVID-19 versus non-COVID-19 pulmonary acute respiratory distress syndrome. Crit Care. 2021;25(1):248. 


\section{Figure legends}

Fig.1. Flowchart of the selection process for the included studies

Fig.2. Forest plot for the association between ventilatory ratio and the mortality of adult ARDS patients. ARDS, acute respiratory distress syndrome; OR, odds ratio; CI, confidence interval

Fig.3. Forest plot for the association between dynamic changes of ventilatory ratio and the mortality of adult ARDS patients. (A. the association based on D1-VR; B. the association based on D2-VR). ARDS, acute respiratory distress syndrome; OR, odds ratio; $\mathrm{CI}$, confidence interval; D1-VR, the value of ventilatory ratio on the first of ventilation; D2-VR, the value of ventilatory ratio on the second of ventilation

Fig.4. Forest plot for the subgroup analysis based on different origin of ARDS. ARDS, acute respiratory distress syndrome; OR, odds ratio; CI, confidence interval; COVID, Corona Virus Disease-19-related ARDS; NON-COVID, Not Corona Virus Disease-19-related ARDS

Fig.5. Forest plot for the subgroup analysis based on definition of mortality. OR, odds ratio; CI, confidence interval

Fig.6. Forest plot for the subgroup analysis based on the researcher. OR, odds ratio; CI, confidence interval

Additional File 1. Checklist.

Additional File 2. Search strategies.

Additional File 3. Assessment of the risk of bias.

Additional File 4. Sensitivity analysis.

Additional File 5. Funnel plot.

Additional File 6. Subgroup analysis. 


\begin{tabular}{|c|c|c|c|c|c|c|c|c|c|c|c|c|c|c|c|c|}
\hline $\begin{array}{l}\text { Study } \\
\text { (year) } \\
\end{array}$ & Setting & Design & Criteria & Origin & $\begin{array}{l}\begin{array}{l}\text { Number } \\
(\text { male\% })\end{array} \\
\end{array}$ & Age (years) & VR & $\mathbf{P} / \mathbf{F}$ & $\begin{array}{c}\text { PEEP } \\
\left(\mathrm{cm} \mathrm{H}_{2} \mathrm{O}\right) \\
\end{array}$ & 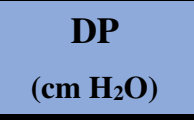 & VD/VT & $\begin{array}{c}\text { Mortality } \\
\text { (definition) }\end{array}$ & OR & $95 \% \mathrm{CI}$ & $\begin{array}{l}\text { IFDs } \\
\text { (days) }\end{array}$ & $\begin{array}{l}\text { VFDs } \\
\text { (days) }\end{array}$ \\
\hline $\begin{array}{l}\text { Sinha, } \\
2019^{6}\end{array}$ & America & $\begin{array}{c}\text { Prospective } \\
\text { observational study }\end{array}$ & AECC & $\mathrm{NA}$ & $520(72 \%)$ & $52 \pm 16$ & $1.9 \pm 0.6$ & $133 \pm 60$ & $\mathrm{NA}$ & NA & $\begin{array}{c}0.57 \pm 0 . \\
17\end{array}$ & $\begin{array}{c}39 \% \\
\text { Hospital } \\
\text { mortality }\end{array}$ & 1.59 & $1.15-2.32$ & $\mathrm{NA}$ & $5(0-21)$ \\
\hline $\begin{array}{l}\text { Sinha1, } \\
2013^{7}\end{array}$ & Australia & Retrospective study & NA & NA & $121(\mathrm{NR})$ & NA & $1.74 \pm 0.58$ & NA & NA & NA & NA & NR & 3.05 & $1.35-6.91$ & NA & NA \\
\hline $\begin{array}{l}\text { Morales- } \\
\text { Ouinteros, } \\
2021^{10}\end{array}$ & $\begin{array}{l}\text { Netherland } \\
\text { 22ICUs }\end{array}$ & $\begin{array}{c}\text { Multicentre } \\
\text { Observational cohort } \\
\text { study }\end{array}$ & NA & COVID & $\begin{array}{c}927 \\
(72.1 \%)\end{array}$ & $\begin{array}{c}65.0 \\
(57.0-72.0 \\
)\end{array}$ & $1.85 \pm 0.64$ & $\begin{array}{c}130.9(99.9-1 \\
75.5)\end{array}$ & $\begin{array}{c}12.7(11.0-14 . \\
5)\end{array}$ & $\begin{array}{c}14.0(12.0-1 \\
6.0)\end{array}$ & NA & $\begin{array}{l}28.7 \% \\
28 \text {-day } \\
\text { mortality }\end{array}$ & 0.99 & $0.78-1.25$ & NA & $\mathrm{NA}$ \\
\hline $\begin{array}{l}\text { Morales-Ou } \\
\text { interos, } \\
2019^{13}\end{array}$ & $\begin{array}{l}\text { Netherland } \\
\text { 2ICUs }\end{array}$ & $\begin{array}{c}\text { Prospective } \\
\text { observational cohort } \\
\text { study }\end{array}$ & Berlin & NA & $940(62 \%)$ & NA & NA & $\mathrm{NA}$ & NA & NA & $\mathrm{NA}$ & $\begin{array}{c}31 \% \\
28 \text {-day } \\
\text { mortality }\end{array}$ & 1.13 & $0.97-1.32$ & $\mathrm{NA}$ & $\mathrm{NA}$ \\
\hline $\begin{array}{l}\text { Torres, } \\
2021^{2}\end{array}$ & $\begin{array}{l}\text { Spanish } \\
\text { 44ICUs }\end{array}$ & $\begin{array}{c}\text { Multicentre } \\
\text { observational cohort } \\
\text { study }\end{array}$ & Berlin & COVID & $\begin{array}{c}1118 \\
(71.2 \%)\end{array}$ & $\begin{array}{c}65.0 \\
(57.0-72.0 \\
)\end{array}$ & $\begin{array}{c}1.73(1.33- \\
2.25)\end{array}$ & $\begin{array}{c}115.6(80.0-1 \\
71.2)\end{array}$ & $\begin{array}{c}12.0(10.0-14 . \\
0)\end{array}$ & $\begin{array}{c}12.0(9.6-15 \\
.0)\end{array}$ & $\mathrm{NA}$ & $\begin{array}{l}38.7 \% \\
\text { Mortality }\end{array}$ & 1.07 & $1.01-1.14$ & NA & $\mathrm{NA}$ \\
\hline $\begin{array}{l}\text { Fusina, } \\
2021^{5}\end{array}$ & Italy & $\begin{array}{c}\text { Retrospective } \\
\text { observational study }\end{array}$ & Berlin & COVID & $187(78.1 \%)$ & NA & NA & $\mathrm{NA}$ & NA & NA & NA & $\begin{array}{l}51.3 \% \\
\text { Hospital } \\
\text { mortality }\end{array}$ & 2.67 & $1.37-5.45$ & $\mathrm{NA}$ & $\mathrm{NA}$ \\
\hline $\begin{array}{l}\text { Sinha2, } \\
2013^{14}\end{array}$ & $\begin{array}{l}\text { ARDS } \\
\text { Network }\end{array}$ & $\begin{array}{c}\text { Retrospective } \\
\text { observational study }\end{array}$ & NA & NA & 1307 & NA & NA & NA & NA & NA & NA & $\begin{array}{l}31.6 \% \\
\text { Hospital } \\
\text { mortality }\end{array}$ & 1.25 & $1.06-1.46$ & NA & $\mathrm{NA}$ \\
\hline $\begin{array}{l}\text { Sinha3, } \\
2013^{15}\end{array}$ & UK & $\begin{array}{c}\text { Retrospective } \\
\text { observational study }\end{array}$ & $\mathrm{NA}$ & $\mathrm{NA}$ & $\begin{array}{c}224 \\
(50.4 \%)\end{array}$ & $\mathrm{NA}$ & NA & $\mathrm{NA}$ & NA & $\mathrm{NA}$ & $\mathrm{NA}$ & NA & 2.34 & $1.03-4.08$ & NA & $\mathrm{NA}$ \\
\hline Ende, $2021^{9}$ & America & $\begin{array}{c}\text { Retrospective } \\
\text { observational cohort } \\
\text { study }\end{array}$ & NA & COVID & $294(68.7 \%)$ & $\mathrm{NA}$ & NA & $\mathrm{NA}$ & NA & NA & NA & $\begin{array}{c}47.6 \\
28 \text {-day } \\
\text { mortality }\end{array}$ & 1.31 & $0.83-2.09$ & NA & $\mathrm{NA}$ \\
\hline
\end{tabular}

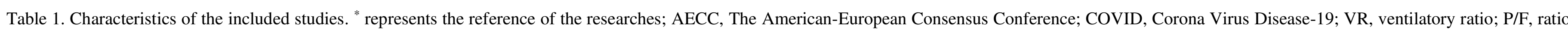

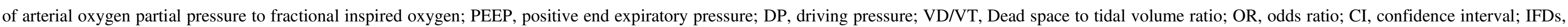
ICU-free days; VFDs, ventilator-free days 


\begin{tabular}{|c|c|c|c|c|c|}
\hline Study & Do & D1 & D2 & D3 & D4-5 \\
\hline $\begin{array}{c}\text { Morales-Ouintero } \\
\text { s, } \\
2019\end{array}$ & NA & $\begin{array}{c}1.13(0.97-1 . \\
32)\end{array}$ & $\begin{array}{c}1.20(1.01-1 . \\
40)\end{array}$ & NA & NA \\
\hline $\begin{array}{l}\text { Morales-Ouintero } \\
\text { s, } 2021\end{array}$ & $\begin{array}{c}0.90(0.71-1 . \\
14)\end{array}$ & $\begin{array}{c}0.99(0.78-1 . \\
25)\end{array}$ & NA & NA & NA \\
\hline $\begin{array}{r}\text { Sinha, } \\
2013\end{array}$ & NA & $\begin{array}{c}1.25(1.06-1 . \\
46)\end{array}$ & $\begin{array}{c}1.20(1.03-1 . \\
41)\end{array}$ & NA & NA \\
\hline $\begin{array}{r}\text { Torres, } \\
2021 \\
\end{array}$ & NA & $\begin{array}{c}1.07 \\
(1.01-1.14) \\
\end{array}$ & NA & $\begin{array}{c}1.04(1.01-1 . \\
07)\end{array}$ & NA \\
\hline $\begin{array}{c}\text { Ende, } \\
2021\end{array}$ & NA & & $1.31(0.83-2.09)$ & & $\begin{array}{c}1.01(0.68-1 \\
50)\end{array}$ \\
\hline
\end{tabular}

Table 2. Dynamic changes of OR on ventilatory ratio. D0 is at the start of ventilation, $\mathrm{D} 1$ is at the first day of ventilation. VR, ventilatory ratio; OR, odds ratio 


\section{Identification of studies via databases and registers}
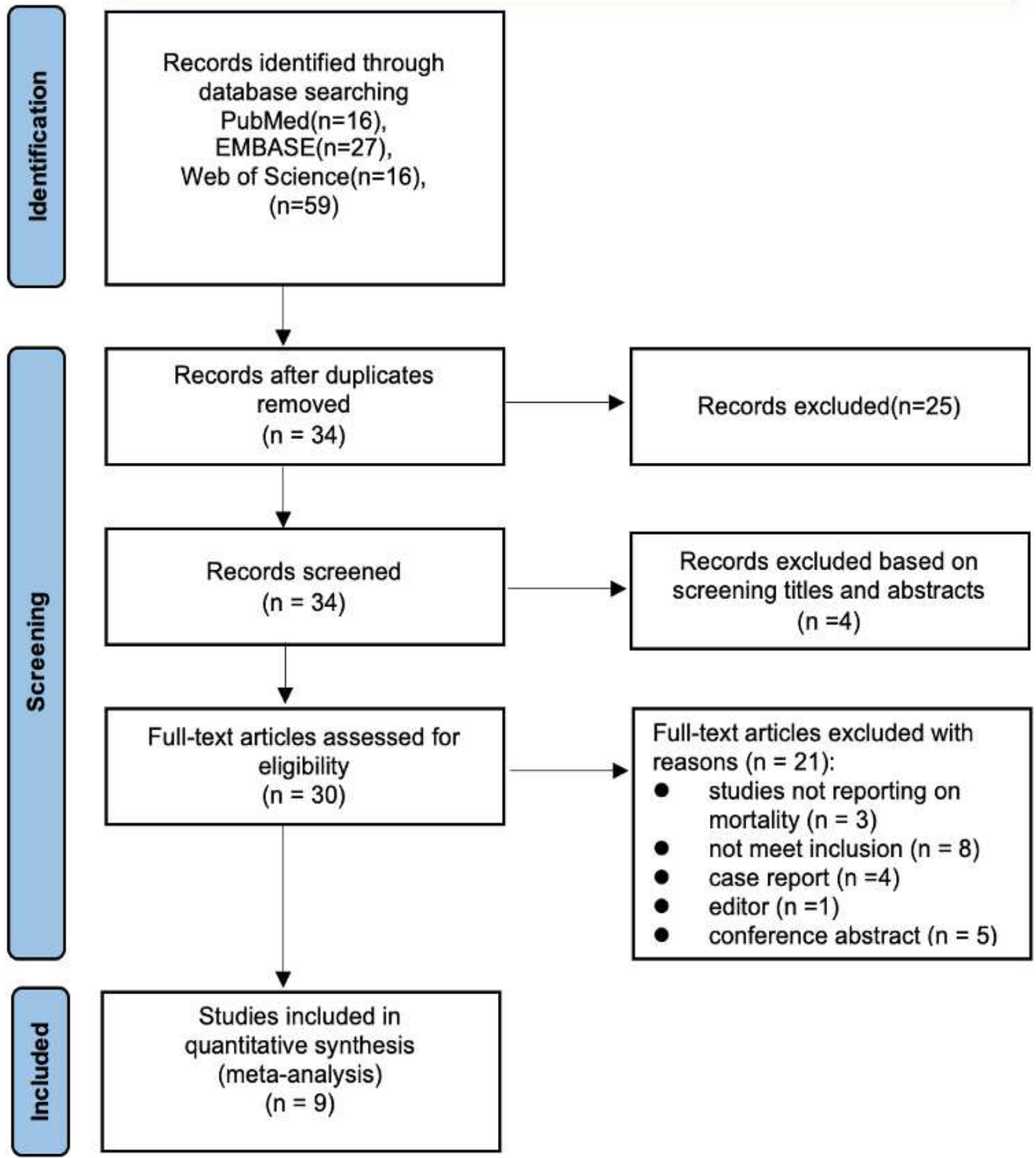

Records excluded based on screening titles and abstracts $(n=4)$
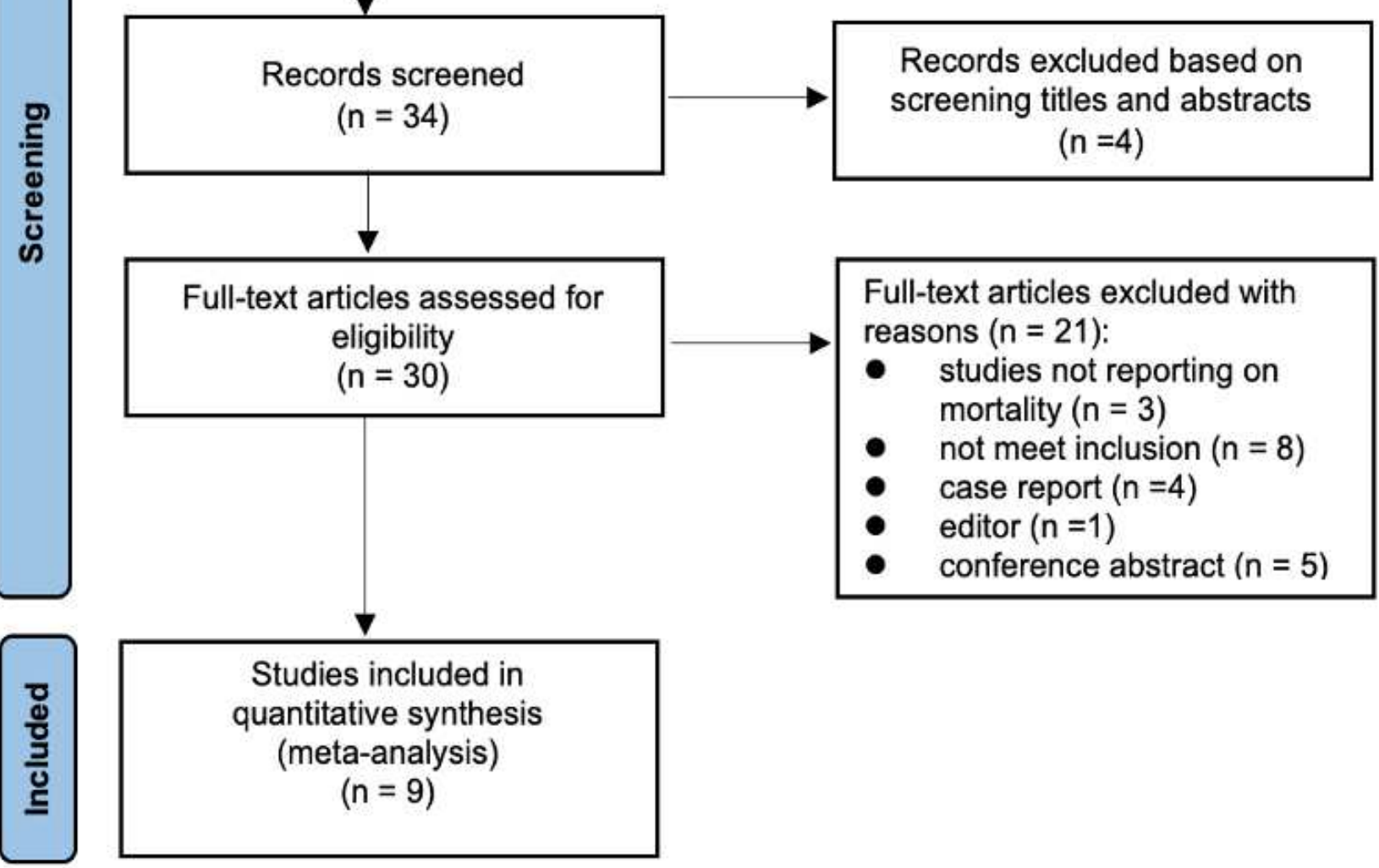

\section{Figure 1}

Flowchart of the selection process for the included studies 


\section{Odds Ratio}

Study or Subgroup

Ende 2021

Fusina 2021

Morales-Ouinteros 2019

Morales-Ouinteros 2021

Sinhal 2013

Sinha 2019

Sinha2 2013

Sinha3 2013

Torres 2021
log[Odds Ratio] SE Weight IV, Random, $95 \% \mathrm{CI}$

$\begin{array}{rrrr}0.27 & 0.2328 & 7.0 \% & 1.31[0.83,2.07] \\ 0.9821 & 0.3404 & 3.9 \% & 2.67[1.37,5.20] \\ 0.1222 & 0.0779 & 18.4 \% & 1.13[0.97,1.32] \\ -0.0101 & 0.1216 & 14.2 \% & 0.99[0.78,1.26] \\ 1.1151 & 0.4158 & 2.8 \% & 3.05[1.35,6.89] \\ 0.4637 & 0.1653 & 10.7 \% & 1.59[1.15,2.20] \\ 0.2231 & 0.0841 & 17.8 \% & 1.25[1.06,1.47] \\ 0.8502 & 0.4187 & 2.7 \% & 2.34[1.03,5.32] \\ 0.0677 & 0.0294 & 22.3 \% & 1.07[1.01,1.13]\end{array}$

$100.0 \%$

$1.27[1.10,1.47]$

Total $(95 \% \mathrm{CI})$

Heterogeneity: $\mathrm{Tau}^{2}=0.02 ; \mathrm{Chi}^{2}=25.44, \mathrm{df}=8(\mathrm{P}=0.001) ; \mathrm{I}^{2}=69 \%$

Test for overall effect: $Z=3.21(P=0.001)$

Risk of bias legend

(A) Representativeness of the exposed cohort

(B) Selection of the non-exposed cohort

(C) Ascertainment of exposure

(D) Demonstration that outcome of interest was not present at start of study

(E) Comparability of cohorts on the basis of the design or analysis

(F) Assessment of outcome

(G) Was follow-up long enough for outcomes to occur

(H) Adequacy of follow up of cohorts

\section{Figure 2}

Forest plot for the association between ventilatory ratio and the mortality of adult ARDS patients. ARDS, acute respiratory distress syndrome; $\mathrm{OR}$, odds ratio; $\mathrm{Cl}$, confidence interval

\begin{tabular}{lrr}
$\begin{array}{l}\text { A } \\
\text { Study or Subgroup }\end{array}$ & log[Odds Ratio] & SE \\
\hline Sinha2 2013 & 0.2231 & 0.0841 \\
Morales-Ouinteros 2019 & 0.1222 & 0.0779 \\
Ende 2021 & 0.27 & 0.2328 \\
& & \\
Total (95\% CI) & \\
Heterogeneity: Chi ${ }^{2}=0.95$, df $=2(P=0.62) ; l^{2}=0 \%$ \\
Test for overall effect: $Z=3.14(P=0.002)$
\end{tabular}

Odds Ratio

SE Weight IV, Fixed, $95 \% \mathrm{CI}$

$43.6 \% \quad 1.25[1.06,1.47]$

$50.8 \% 1.13[0.97,1.32]$

$5.7 \% \quad 1.31[0.83,2.07]$

$100.0 \% \quad 1.19[1.07,1.33]$

Test for overall effect: $Z=3.14(P=0.002)$

B

\begin{tabular}{lrr} 
Study or Subgroup & log[Odds Ratio] & SE \\
\hline Sinha2 2013 & 0.1823 & 0.0779 \\
Morales-Ouinteros 2019 & 0.1823 & 0.0879 \\
Ende 2021 & 0.27 & 0.2328 \\
& & \\
Total $(95 \% \mathrm{CI})$ & \\
Heterogeneity: Chi ${ }^{2}=0.13, \mathrm{df}=2(\mathrm{P}=0.94) ; \mathrm{I}^{2}=0 \%$ \\
Test for overall effect: $\mathrm{Z}=3.32(\mathrm{P}=0.0009)$
\end{tabular}

Odds Ratio Weight IV, Fixed, $95 \% \mathrm{CI}$ $52.7 \% 1.20[1.03,1.40]$ $41.4 \% 1.20[1.01,1.43]$ $5.9 \% 1.31[0.83,2.07]$

$100.0 \% \quad 1.21[1.08,1.35]$

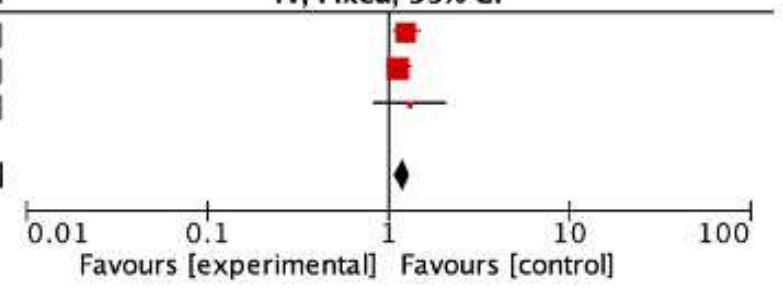

Odds Ratio IV, Fixed, $95 \% \mathrm{CI}$

Odds Ratio IV, Fixed, $95 \% \mathrm{Cl}$

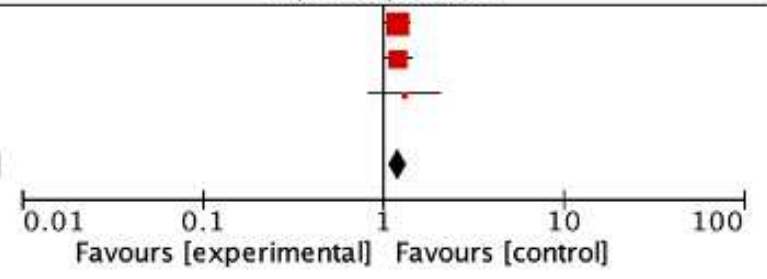

\section{Figure 3}

Forest plot for the association between dynamic changes of ventilatory ratio and the mortality of adult ARDS patients. (A. the association based on D1-VR; B. the association based on D2-VR). ARDS, acute respiratory distress syndrome; $\mathrm{OR}$, odds ratio; $\mathrm{Cl}$, confidence interval; $\mathrm{D} 1-\mathrm{VR}$, the value of ventilatory ratio on the first of ventilation; D2-VR, the value of ventilatory ratio on the second of ventilation 


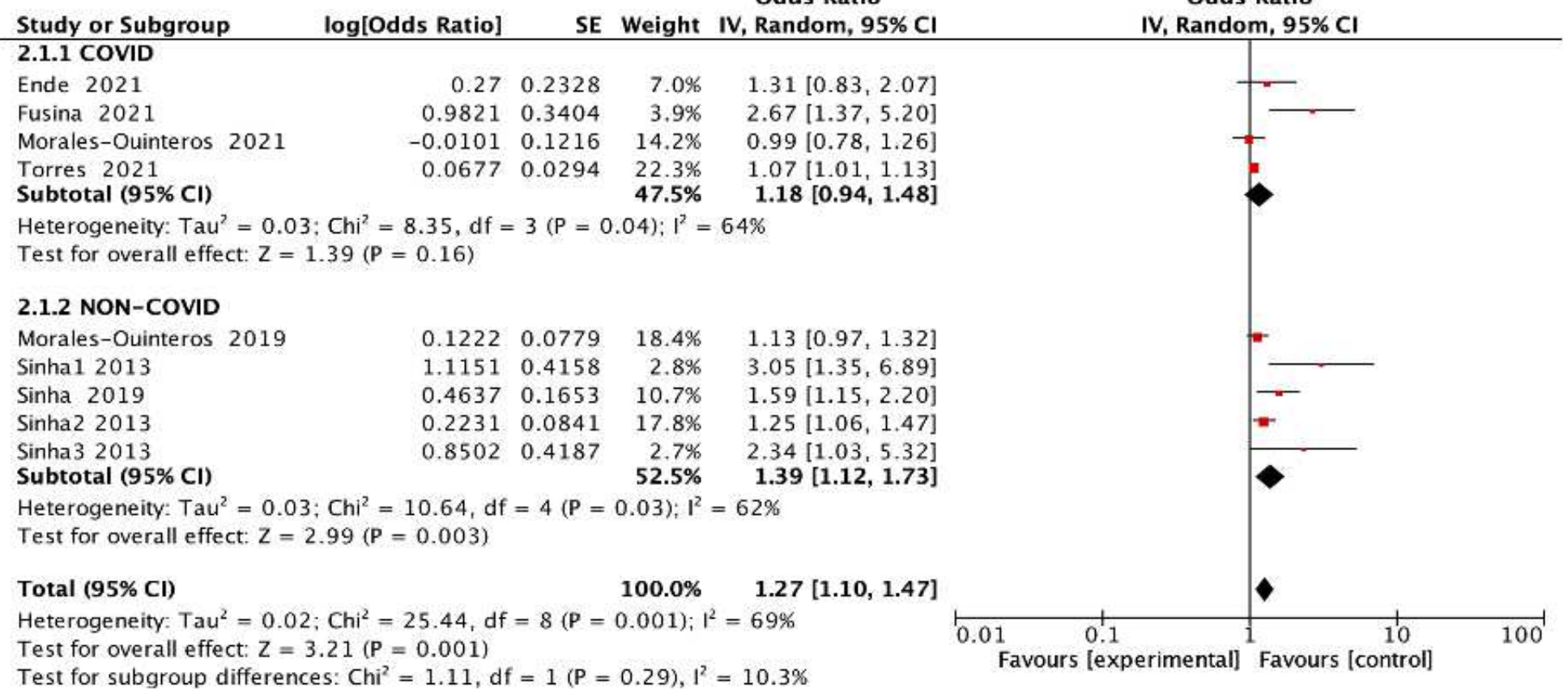

\section{Figure 4}

Forest plot for the subgroup analysis based on different origin of ARDS. ARDS, acute respiratory distress syndrome; OR, odds ratio; $\mathrm{Cl}$, confidence interval; COVID, Corona Virus Disease-19-related ARDS; NONCOVID, Not Corona Virus Disease-19-related ARDS

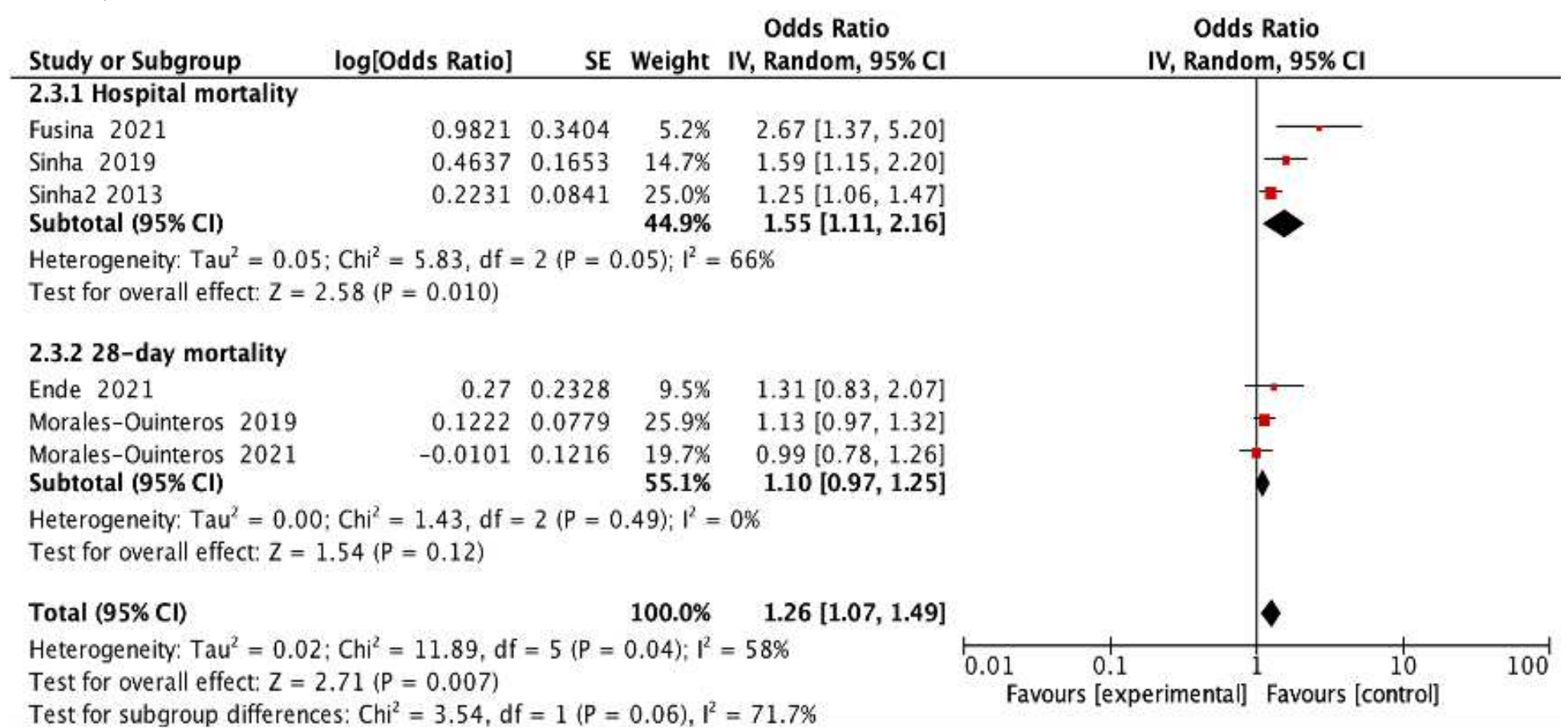

\section{Figure 5}

Forest plot for the subgroup analysis based on definition of mortality. OR, odds ratio; $\mathrm{Cl}$, confidence interval 


\subsubsection{Sinha}

Sinha 12013

Sinha 2019

Sinha2 2013

Sinha3 2013

Subtotal $(95 \% \mathrm{CI})$

Heterogeneity: $\mathrm{Tau}^{2}=0.06 ; \mathrm{Chi}^{2}=7.34, \mathrm{df}=3(\mathrm{P}=0.06) ; \mathrm{I}^{2}=59 \%$

Test for overall effect: $Z=2.91(P=0.004)$

\subsubsection{NON-Sinha}

Ende 2021

Fusina 2021

Morales-Ouinteros 2019

Morales-Ouinteros 2021

Torres 2021

Subtotal $(95 \% \mathrm{CI})$

$\begin{array}{rrrr}1.1151 & 0.4158 & 2.8 \% & 3.05[1.35,6.89] \\ 0.4637 & 0.1653 & 10.7 \% & 1.59[1.15,2.20] \\ 0.2231 & 0.0841 & 17.8 \% & 1.25[1.06,1.47] \\ 0.8502 & 0.4187 & 2.7 \% & 2.34[1.03,5.32] \\ & & \mathbf{3 4 . 1 \%} & \mathbf{1 . 6 2}[1.17,2.25]\end{array}$

$\begin{array}{llll}1.1151 & 0.4158 & 2.8 \% & 3.05[1.35,6.89]\end{array}$

$0.22310 .0841 \quad 17.8 \% \quad 1.25[1.06,1.47]$

$\begin{array}{llll}0.8502 & 0.4187 & 2.7 \% & 2.34[1.03,5.32]\end{array}$

$1.62[1.17,2.25]$

$\begin{array}{rrrr}0.27 & 0.2328 & 7.0 \% & 1.31[0.83,2.07] \\ 0.9821 & 0.3404 & 3.9 \% & 2.67[1.37,5.20] \\ 0.1222 & 0.0779 & 18.4 \% & 1.13[0.97,1.32] \\ -0.0101 & 0.1216 & 14.2 \% & 0.99[0.78,1.26] \\ 0.0677 & 0.0294 & 22.3 \% & 1.07[1.01,1.13] \\ & & 65.9 \% & 1.12[0.98,1.29]\end{array}$

Heterogeneity: $\mathrm{Tau}^{2}=0.01 ; \mathrm{Chi}^{2}=8.70, \mathrm{df}=4(\mathrm{P}=0.07) ; \mathrm{I}^{2}=54 \%$

Test for overall effect: $Z=1.71(P=0.09)$

Total (95\% Cl)

$100.0 \% \quad 1.27[1.10,1.47]$

Heterogeneity: $\mathrm{Tau}^{2}=0.02 ; \mathrm{Chi}^{2}=25.44, \mathrm{df}=8(\mathrm{P}=0.001) ; \mathrm{I}^{2}=69 \%$

Test for overall effect: $Z=3.21(P=0.001)$

Test for subgroup differences: $C^{2} i^{2}=4.15, d f=1(P=0.04), I^{2}=75.9 \%$

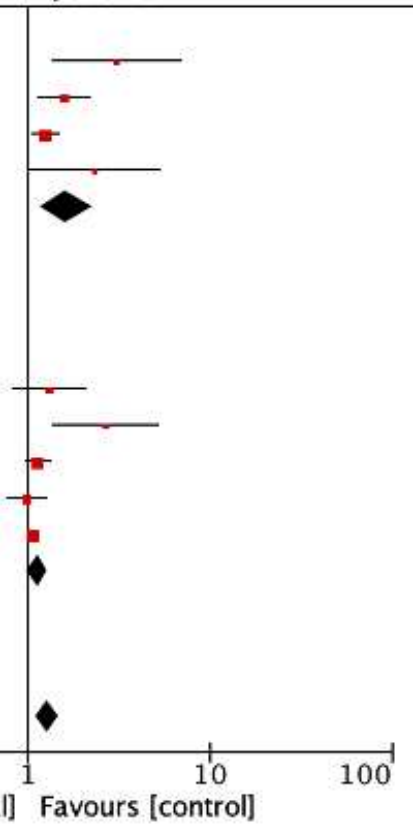

Figure 6

Forest plot for the subgroup analysis based on the researcher. OR, odds ratio; $\mathrm{Cl}$, confidence interval

\section{Supplementary Files}

This is a list of supplementary files associated with this preprint. Click to download.

- AdditionalFile1.Checklist.docx

- AdditionalFile2.Searchstrategy.docx

- AdditionalFile3.Assessmentoftheriskofbias.doc

- AdditionalFile4.Sensitivityanalysis.docx

- AdditionalFile5.Funnelplot.pdf

- AdditionalFile6.Subgroupanalysis.pdf 